\title{
Urban Crime Safety Evaluation Model
}

\author{
Hao Zheng ${ }^{1, a}$ \\ ${ }^{1}$ North China Electric Power University, Beijing ,China,102206 \\ ${ }^{a}$ email,
}

\begin{abstract}
Keywords: City Safety, Crime, System Clustering, SOM Neutral Network, Multi-Index Comprehensive Evaluation
\end{abstract}

\begin{abstract}
Recently IS organization is increasingly rampant and the frequent occurrence of cases similar to Paris attacks highlight city safety problem increasingly. City safety grade evaluation becomes a more and more important topic. Based on a sample of 378 U.S. cities, the paper uses the multi-objective comprehensive evaluation model and SOM neural network algorithm to evaluate the safety grade of the target city.

Firstly, we find two important indexes affecting the safety of the city: crime rate and arrest rate. Due to particularly prominent influence of severe crimes on city security, we decided to use the crime rate and arrest rate of seven categories of cases (murder, rape, robbery, beating, burglary, theft, and motor vehicle theft) as evaluation index of city security. Secondly, based on the above indexes, we analyze and summarize the crime data in 378 cities in 2014 on the official website, using the consistency coefficient of system clustering. The result shows that the optimal class number is 24 , namely 24 safety levels are divided. Then, we use SOM neural network algorithm to train the samples, determine the weight of each index. Finally, we use multi-index comprehensive evaluation model to evaluate the safety level of the target city.

We will change the competitive layer of model and the frequency of training, and find that the security level error is no more than $5 \%$. It shows the model withstand the test with certain stability and accuracy. Besides, the model uses system clustering to determine the classification number, and determine the weights by using SOM neural network algorithm. It is thus clear that the result is highly scientific. In addition, the applicable scope of model is extremely broad. As for the multi-index comprehensive evaluation problems, our model is instructive and of practical significance.
\end{abstract}

\section{Introduction}

City is a highly clustered area of population, industry and wealth. With the development of economy, the urban population has increased sharply and the city is facing increasingly serious security issues. City safety involves the urban disaster prevention, public security, economic security, ecological environment, health care, emergency rescue, security management and many other aspects. City safety degree is directly related to the physical and mental health of urban residents, the stability of the urban public order and the urban social and economic development. The evaluation on the urban security can be effective in the diagnosis of the city's safety status, troubleshooting the hidden trouble existing in the urban system and improving the safety management of cities. It is an integral part of modern city safety management. Urban crime is one of our most concerns. In the big and small cities, all kinds of crimes happen every day. A reasonable algorithm can achieve safety grade evaluation for each city in a short period of time to further solve the problem of city security. The goal of this article is to divide the city security levels in a reasonable manner, so as to assess the urban safety level.

The topic gives two weeks of crime data of this city, including case time, type, site, and whether the arrest. It is required to establish a model and algorithm analysis of the data in the attachment, create a set of safety grade evaluation system. In the end, use the system to evaluate safety grade of this city. 


\section{Assumption}

Assume that the city level of the target city relates to number of crimes, kind of crimes and arrest rate

Assume that the number of crimes and the arrest rate in the target city in proportion to urban population.

Assume that the average value of various indexes in 14 days refers to the average value of each year.

\section{Symbols Definition}

Table 1: Notation

\begin{tabular}{|c|c|}
\hline Symbol & Meaning \\
\hline$x$ & Number of j crimes in city i (every 100,000 people) \\
\hline$v$ & Number of arrest in city i (every 100,000 people) \\
\hline$N$ & Safety level of the city \\
\hline$R R^{\prime}$ & Data before and after conversion in target city \\
\hline$d .$. & Euler distance \\
\hline$Y$ & Various crime indexes of the target city \\
\hline
\end{tabular}

\section{Urban Crime Safety Evaluation Model}

Index of Urban Safety Evaluation. According to the International standard for urban safety evaluation, the urban safety level is determined by factors like the crime rate, crime type, violence degree, and arrest rate.

We divide crime into vicious crime and non-vicious crime, according to the type of crime and the extent of harm to city security. It is known that the non-vicious crime has little impact on urban safety, which can be ignored. So we can say that city security is mainly affected by vicious crime. Vicious crime contains two types, violent crime and property crime. Violent crime includes murder, rape, robbery and beating. Property crime consists of burglary, theft and motor vehicle theft.

Date Acquisition and Analysis. We use Excel to get the following form about the number of crimes and arrest rate in target city.

Table 2: Number of crimes and arrest within 14 days in target city

\begin{tabular}{|c|c|}
\hline $\begin{array}{c}\text { Crime type and total arrest } \\
\text { number in target city }\end{array}$ & $\begin{array}{c}\text { Number of cases in } \\
\text { 14 days }\end{array}$ \\
\hline Violent crime & 1158 \\
\hline Murder & 20 \\
\hline Rape & 23 \\
\hline Rob & 403 \\
\hline Beating & 712 \\
\hline Property crime & 3606 \\
\hline Burglary & 566 \\
\hline Burglar & 2658 \\
\hline Motor vehicle theft & 382 \\
\hline Arrest number & 596 \\
\hline
\end{tabular}


We regard the data in 14 days as a typical sample in 365 days, namely considering the average number of various crimes and arrest rate in 14 days is the average number of 365 days. Upon conversion, we can get the number of crime and arrest rate.

$$
\frac{R}{14} \times \frac{365}{280000000} \times 100000=R^{\prime}
$$

$\mathrm{R}$ denotes the data before and after conversion in target city

Table 3: The number of cases and total arrest number among 100,000 populations in target city

\begin{tabular}{|c|c|}
\hline $\begin{array}{c}\text { Crime type and total arrest number } \\
\text { in target city }\end{array}$ & $\begin{array}{c}\text { Number of cases in the year } \\
\text { (every 100,000 people) }\end{array}$ \\
\hline Violent crime & 1078.2 \\
\hline Murder & 18.6 \\
\hline Rape & 21.4 \\
\hline Rob & 375.2 \\
\hline Beating & 663 \\
\hline Property crime & 3357.6 \\
\hline Burglary & 527 \\
\hline Burglar & 2474.9 \\
\hline Motor vehicle theft & 355.7 \\
\hline Arrest number & 554.9 \\
\hline
\end{tabular}

As is shown in the table, we may see the number of financial crimes is more than 3 times of violent crimes. The beating and rob crimes account for a higher degree in violence crimes; the theft crimes account for a higher degree in property crime. The arrest rate is about $12.5 \%$.

In order to evaluate the safety level in the target city, we should seek for the other cities indexes as sample. We find the number of crimes and arrest rate of 378 American cities in 2014 on FBI website. Upon statistics, we get data as follows:

Table 4: Number of crimes and total arrest number in 2014 among 100,000 populations in 10 cities

\begin{tabular}{|c|c|c|c|c|c|c|c|c|}
\hline $\begin{array}{c}\text { City } \\
\text { Crime type }\end{array}$ & San Diego & $\begin{array}{c}\text { San } \\
\text { Antonio }\end{array}$ & $\begin{array}{c}\text { Los } \\
\text { Angeles }\end{array}$ & Houston & Flint & Detroit & St. Louis & Bridgeport \\
\hline $\begin{array}{c}\text { Violent } \\
\text { crime }\end{array}$ & 325.2 & 404.9 & 368.9 & 567.4 & 652.2 & 529.4 & 429.8 & 244.6 \\
\hline Murder & 2.3 & 5.8 & 4.4 & 5.8 & 7.7 & 8.7 & 8.8 & 1.9 \\
\hline Rape & 23.4 & 59.4 & 21.6 & 33.2 & 69.9 & 44.9 & 35.8 & 20 \\
\hline Rob & 83.1 & 87.1 & 136.6 & 232.2 & 117.1 & 125.5 & 103.4 & 100 \\
\hline Beating & 216.4 & 252.6 & 206.2 & 296.1 & 457.5 & 350.3 & 281.8 & 122.7 \\
\hline $\begin{array}{c}\text { Property } \\
\text { crime }\end{array}$ & $1,813.50$ & $4,197.60$ & $2,050.40$ & $3,208.10$ & $2,733.80$ & $2,203.70$ & $2,449.20$ & $1,606.20$ \\
\hline Burglary & 336.6 & 729.5 & 402.8 & 688.6 & 880.1 & 467.1 & 470.4 & 304 \\
\hline $\begin{array}{c}\text { Burglar } \\
\text { Motor }\end{array}$ & $1,186.30$ & $3,105.80$ & $1,324.60$ & $2,132.60$ & $1,718.00$ & $1,353.00$ & $1,765.00$ & $1,146.20$ \\
\hline $\begin{array}{c}\text { vehicle theft } \\
\text { Arrest } \\
\text { number }\end{array}$ & 674.6 & 362.2 & 323 & 387 & 135.7 & 383.5 & 213.8 & 155.9 \\
\hline
\end{tabular}


The above is the summary and analysis of target data and sample data. Next, we plan to use SOM neutral network for calculation.

Optimal Class Number. We use the inconsistent coefficient in Hierarchical $w_{i j}$ Cluster analysis process to judge.

Steps:

1. Input the sample data of 378 cities in America and conduct standardization;

2. Use pdist function to calculate the distance; is Euclidean distance

3. Use inconsistent function to calculate inconsistent coefficient;

4. Determine the best number of hierarchy: 24.

Introductions of SOM Neural Network Algorithm. SOM is a kind of unsupervised feed-forward network, which conducts the self-organization learning through the competition in training, extracts the data characteristics or some inherent law and classifies the samples. SOM neural network is composed of input layer and output layer, as shown in Figure 1 . The interconnection is conducted between input layer and output layer. The nerve cell in output layer implements lateral confinement connection. Each input connects each neuron the in output layer through the weights. Nerve cell in output layer is a two-dimensional array, each neuron is a representative of the input samples of them.

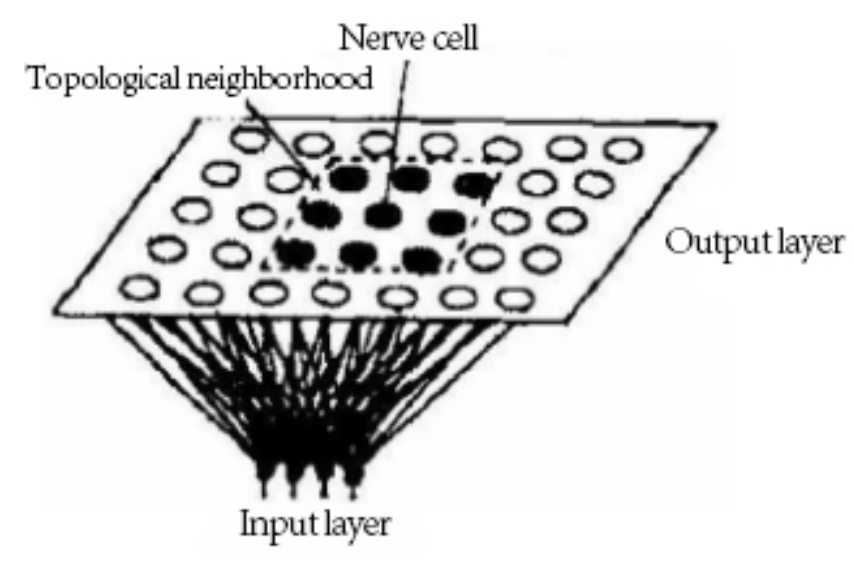

Figure $1 \quad$ SOM neurons network model

SOM learning algorithms include: competition, cooperation and update process. In the stage of cooperation, determine the largest neurons is winning neurons; in cooperation stage, determine the center of winning neuron is neurons neighborhood winning neuron within the scope, which is also known as excited neurons; In updating stage, adopt the Hebb learning rule change form to upgrade the weight vector of winning neuron.

As for training sample vector set $\mathrm{X}$, the number of samples $\mathrm{t}$ and it is element of $\mathrm{X}$. The number of input neuron is $\mathrm{k}$, namely it indicates the sample vector dimension. The number of output neuron is $h$, indicating the number of categories. Establish $h$ two-dimension grid of output neuron. The weight from each input neuron to each output neuron is namely is the $\mathrm{j} w_{i j}(i \in[1, h], j \in[1, k])$ element.

Concrete Calculation. Training of sample data. Input sample data P (378 cities in America);

2. Determine competitive layer [6 4] and use newsom to establish $y_{i}$ neural network;
3. Determine training number $\mathrm{a}=1000$;

4. Train and classify samples.

(1)Weight initialization is weight vector. Use smaller random vector to initialize. The number of iterations is $\mathrm{N}$; the initial learning rate is

(2)Randomly select a training vector as $\eta(0)$ input in sample set X;

(3)Use forum (2) to determine winning $x_{q}$ neuron 


$$
W_{i}(n+1)=\left\{\begin{array}{l}
W_{i}(n)+\eta(n)\left(x_{q}-W_{i}(n)\right), i \in N e(n) \\
W_{i}(n), \text { others }
\end{array}\right\}
$$

(4)Upgrade weight vector of excited neuron in topology neighborhood $N e(n)$ in winning neuron

$$
\left\|x_{q}-W_{V}\right\|=\min _{i}\left\|x_{q}-W_{i}\right\|, i=1,2, \cdots, h
$$

Where, $\eta(n)(0<\eta(n)<1)$ is learning step. It decreases as $n$ decreases, to guarantee the convergence of learning process;

(5)Upgrade learning rate and topology neighborhood

$$
P=\left\{\begin{array}{l}
x_{11}, x_{12}, x_{13}, x_{14}, x_{15}, x_{16}, x_{17}, x_{18}, x_{19}, \mathrm{y}_{1} \\
x_{21}, x_{22}, x_{23}, x_{24}, x_{25}, x_{26}, x_{27}, x_{28}, x_{29}, \mathrm{y}_{2} \\
\cdots \ldots . . \\
x_{3781}, x_{3782}, x_{378}, x_{3784}, x_{3785}, x_{3786}, x_{378}, x_{378}, x_{378}, \mathrm{y}_{378}
\end{array}\right\}
$$

(6) Repeat step (2) and (3) until learning all samples, completing training of SOM neutral network and getting the input vector cluster.

Analysis of training results

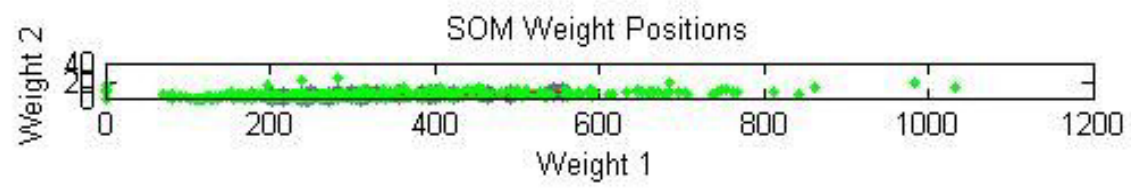

Fig. 2 Training results of sample city

In the Figure, the safety level in all cities is in inclined left, we may see the safety level is slightly dangerous. 


\section{The number of cities contained in each safety level}

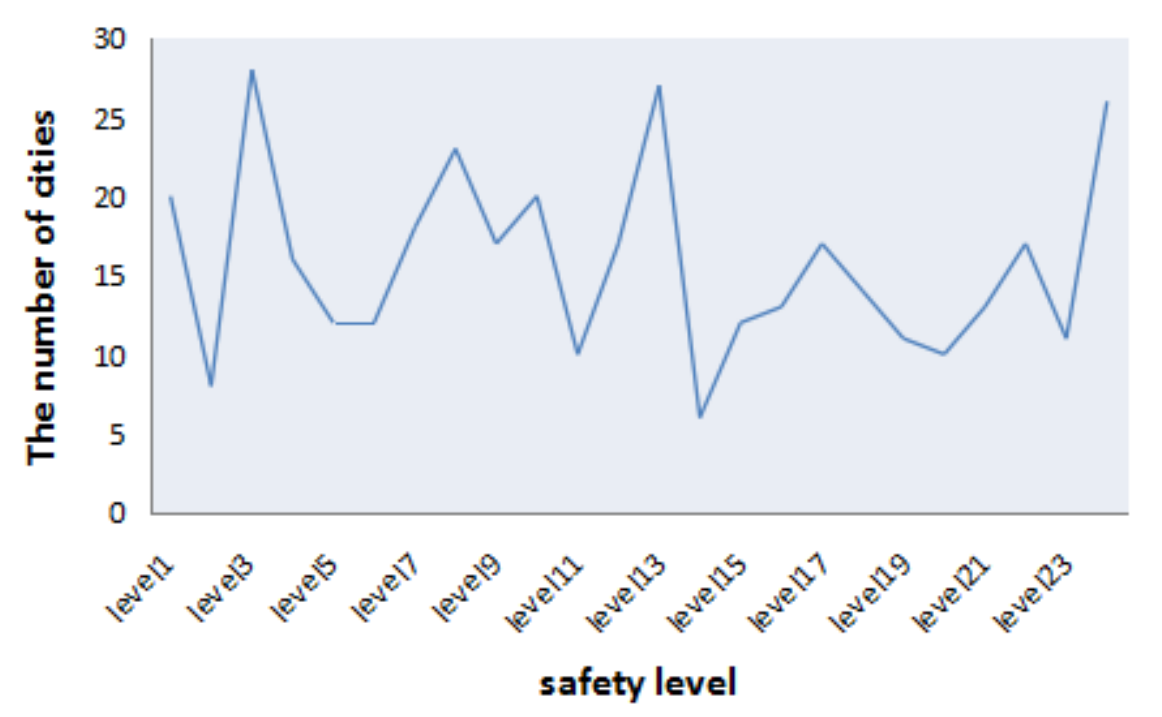

Fig. 3Line chart of city number in 24 safety levels

The safety level in 378 cities is distributed in 24 standards in normal state. The figure is higher, it is more dangerous. The figure is small, it is safer. We can see the number of the safest level is 20 and the most dangerous level is 27.

Find safety level of target city.

1. Use training sample to judge the target data. Input the target data $\mathrm{X}$ into vec2ind function to calculate

$$
X=[1078.2,18.6,21.4,375.2,663,3357.6,527,2474.9,355.7,554.9]
$$

2. Upon calculation, get the safety level $\mathrm{N}=12$ in target level. The city falls at the middle level. Sensitivity analysis

1. Change the training number of sample city from $a=1000$ to $a=800$ and get the iteration result as follows:

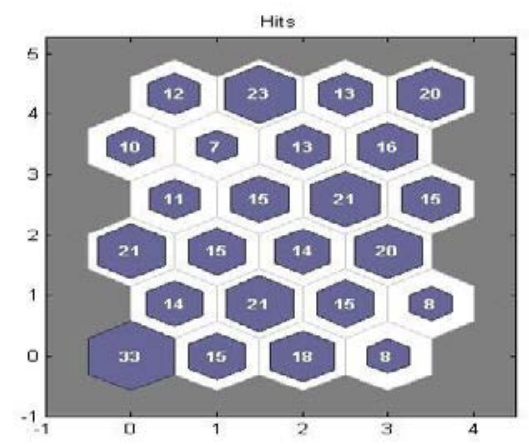

Fig. 4 Iteration result after training number changes to 800

We may discover that the city safety level still is close to the training result of $a=1000$. Use vec2ind function to calculate the safety level of target city: $\mathrm{N}=13$. It is in middle level.

2. Change the training number of sample city from $a=1000$ to $a=1200$ and get the iteration result as follows: 


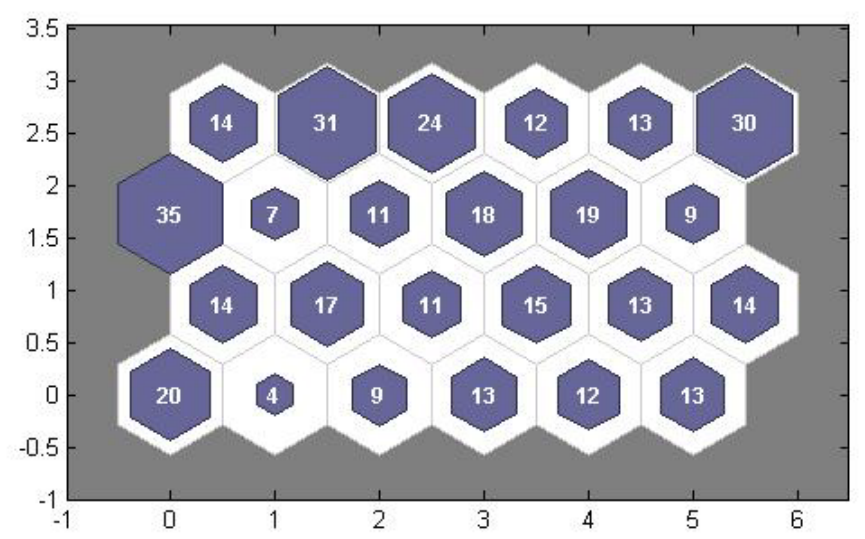

Figure 5 Iteration result after training number changes to 1200

We may discover that the city safety level still is close to the training result of $a=1000$. Use vec2ind function to calculate the safety level of target city: $\mathrm{N}=12$. It is in middle level.

3. Change the competitive layer of SOM neural network algorithm [12 2], training number $\mathrm{a}=1000$ and get the safety evaluation result of sample city:

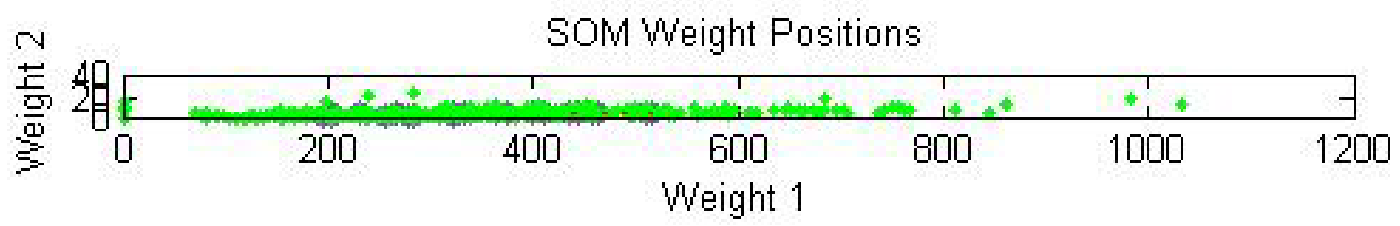

Figure 6 Training results of sample city after changes of competitive layer

We may discover that the city safety level still is close to the training result (1000). Use vec2ind function to calculate the safety level of target city: $\mathrm{N}=15$; it is in dangerous level;

\section{Discussion and Conclusion}

Strengths. High reliability: The sensitivity analysis shows our model is reliable and stable. The target achievements show the city is in middle safety level under the training numbers and competitive layer conditions. Even though sometimes it is a bit more dangerous, it is still in the allowable error scope. So we can find the model safe and reliable.

Convenient and fast: The model only uses one SOM neural network algorithm, which is simple, effective and fast. We can use MATLAB to calculate and evaluate the safety level of a city within 5 minutes.

High scientificity: SOM neural network algorithm is not regulated for the weight balance of each index. We may get the best weight with scientific calculation methods to greatly reduce the influence of man-made objective factors, which is with higher practicality and objectiveness.

High precision: There are 24 safety levels. We may accurately know what the safety level of the target city.

Weaknesses. We ignore the crime time, venue and domestic influence on urban security crime. Moreover, we take the American cities as a sample not on behalf of all the world's cities. So the results have some limitations. In spite of this, our model on safety evaluation still has certain 
guiding significance.

\section{Model Generalization}

Our model can not only be used to evaluate urban safety level, but also the problem of multi-index comprehensive evaluation such as food safety level evaluation, land quality level evaluation and so on can be evaluated by our model. Therefore, the model has a high significance and strong practicality. It also has guidance and reference significance for multi-index evaluation problem.

\section{Reference}

[1] The FBI Uniform Crime Reports Crime Stats for 2014 https://www.fbi.gov/about-us/cjis/ucr/crime-in-the-u.s/2014/crime-in-the-u.s.-2014/offenses-kn own-to-law-enforcement/violent-crime

[2] Property Crime Wikipedia https://en.wikipedia.org/wiki/Property_crime

[3] Violent Crime Wikipedia https://en.wikipedia.org/wiki/Violent_crime

[4] Self-organizing map Wikipedia https://en.wikipedia.org/wiki/Self-organizing_map

[5] Qi Zhi, research of clustering visualization methods based on SOM neural network, Northeast Normal University, 2009.

[6] Yang Zhanhua and Yang Yan, research and process of SOM neural network algorithm [J], computer engineering, 2006.

[7] Xie Zhonghua, MATLAB statistical analysis and application [M], Beijing University of Aeronautics and Astronautics Press, 2010.

[8] Chen Chao, Research of MATLAB application examples, Electronic Industry Press, 2010.

[9] Jiang Qiyuan, et. al, Mathematical model (edition 4),Beijing HIGHER Education Press, 2011.

[10] An Improved Self-Organizing Map Neural Network Approach to Path Planning of a Multi-robot System,Simon X. Yang; Max Q. -H. Meng, Proceedings of China intelligent automation conferences in 2003.

[11] A Quantum Self-Organizing Mapping Neural Network, LI Penghua; CHAI Yi; CEN Ming; LIU Nian; QIU Yifeng, Proceedings of the 32th China control conferences, 2013.

[12] Self-Organizing Map Based Quality Assessment for Resistance Spot Welding with Featured Electrode Displacement Signals, Wang Shaungyuan, Gong Liang and Liu Chengliang,Journal of Shanghai Jiaotong University(Science),2012 